\title{
Cocktails of pesticide residues in conventional and organic farming systems in Europe - Legacy of the past and turning point for the future
}

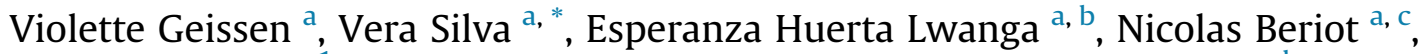 \\ Klaas Oostindie a, ${ }^{a}$, Zhaoqi Bin ${ }^{a}$, Erin Pyne ${ }^{a}$, Sjors Busink ${ }^{a}$, Paul Zomer ${ }^{\mathrm{d}}$, Hans Mol ${ }^{\mathrm{d}}$, \\ Coen J. Ritsema ${ }^{a}$ \\ a Soil Physics and Land Management Group, Wageningen University \& Research, Wageningen, the Netherlands \\ ${ }^{\mathrm{b}}$ Agroecología, El Colegio de La Frontera Sur - Unidad Campeche, Campeche, Mexico \\ c Sustainable Use, Management and Reclamation of Soil and Water Research Group, Universidad Politécnica de Cartagena, Cartagena, Spain \\ ${ }^{\mathrm{d}}$ Wageningen Food Safety Research, Part of Wageningen University \& Research Wageningen, the Netherlands
}

\section{A R T I C L E I N F O}

\section{Article history:}

Received 31 October 2020

Received in revised form

21 January 2021

Accepted 21 February 2021

Available online 8 March 2021

\section{Keywords:}

Mixtures of pesticide residues

EU agricultural soils

Organic and conventional farming

\begin{abstract}
A B S T R A C T
Considering that pesticides have been used in Europe for over 70 years, a system for monitoring pesticide residues in EU soils and their effects on soil health is long overdue. In an attempt to address this problem, we tested $340 \mathrm{EU}$ agricultural topsoil samples for multiple pesticide residues. These samples originated from 4 representative EU case study sites (CSS), which covered 3 countries and four of the main EU crops: vegetable and orange production in Spain ( $\mathrm{S}-\mathrm{V}$ and $\mathrm{S}-\mathrm{O}$, respectively), grape production in Portugal ( $\mathrm{P}-$ $\mathrm{G}$ ), and potato production in the Netherlands (N-P). Soil samples were collected between 2015 and 2018 after harvest or before the start of the growing season, depending on the CSS. Conventional and organic farming results were compared in $\mathrm{S}-\mathrm{V}, \mathrm{S}-\mathrm{O}$ and $\mathrm{N}-\mathrm{P}$. Soils from conventional farms presented mostly mixtures of pesticide residues, with a maximum of 16 residues/sample. Soils from organic farms had significantly fewer residues, with a maximum of 5 residues/sample. The residues with the highest frequency of detection and the highest content in soil were herbicides: glyphosate and its main metabolite AMPA (P-G, N-P, S-O), and pendimethalin ( $\mathrm{S}-\mathrm{V})$. Total residue content in soil reached values of $0.8 \mathrm{mg} \mathrm{kg}^{-1}$ for $\mathrm{S}-\mathrm{V}, 2 \mathrm{mg} \mathrm{kg}^{-1}$ for $\mathrm{S}-\mathrm{O}$ and $\mathrm{N}-\mathrm{P}$, and $12 \mathrm{mg} \mathrm{kg}^{-1}$ for P-G. Organic soils presented 70 $-90 \%$ lower residue concentrations than the corresponding conventional soils. There is a severe knowledge gap concerning the effects of the accumulated and complex mixtures of pesticide residues found in soil on soil biota and soil health. Safety benchmarks should be defined and introduced into (soil) legislation as soon as possible. Furthermore, the process of transitioning to organic farming should take into consideration the residue mixtures at the conversion time and their residence time in soil.

( $) 2021$ The Author(s). Published by Elsevier Ltd. This is an open access article under the CC BY license (http://creativecommons.org/licenses/by/4.0/).
\end{abstract}

\section{Introduction}

Farming systems in Europe rely strongly on the use of pesticides to secure yields in plant production and animal husbandry, with farmers using an average of 340,000 to 370,000 tons of active substances annually (FAOSTAT, 2019). As a result of such intensive pesticide use, multiple pesticide residues are commonly found in

\footnotetext{
This paper has been recommended for acceptance by Da Chen.

* Corresponding author.

E-mail address: vera.felixdagracasilva@wur.nl (V. Silva).

${ }^{1}$ He passed away during the revision process.
}

soil (Silva et al. 2019), water (Casado et al., 2019), food and feed (EFSA, 2020), and humans (Bevan et al., 2017). Of the 487 active substances approved for sale in the EU market (EC, 2020a), almost $50 \%$ are bioaccumulative, $25 \%$ are persistent in soil $\left(\mathrm{DT}_{50}>100\right.$ days; PPDB, 2020), 30\% have a high acute aquatic toxicity, and 28 are suspected carcinogens (EC 2008a). These and other related figures raise serious concerns about the impact of pesticides on the health of ecosystems, animals and humans.

The effects of pesticides on organisms are assessed following European Food Safety Authority (EFSA), Organisation for Economic Co-operation and Development (OECD) and International Standards Organisation (ISO) standards and guidance documents, 
which relate to the direct effects of individual active substances on single species. Similarly, pre-market approval of new pesticides is focused on risks and impacts of individual active substances and pesticide formulations. Current pesticide approval protocols take into account only a limited range of environmental and health indicators and non-target organisms. A recent EFSA report (EFSA, 2019) describes procedures for the assessment of the effects of mixtures. However, data and procedures relating to the long-term effects of pesticide residues' mixtures on non-standard and native species and communities are not yet available. In the meantime, serious pesticide adverse effects have been observed in different taxa, including beneficial insects and pollinators (Grubisik et al., 2018; Sanchez-Bayo and Wyckhuys 2019). For example, neonicotinoids have been proven to cause bee mortality (Colin et al., 2019) and are therefore restricted in Europe. Additionally, recent studies have shown that the changes in the gut microbiome of bees following glyphosate exposure reduces resilience, making the bees more susceptible to diseases (Motta et al., 2018). Although scientists have discussed the idea that pesticide use is one of the main reasons for the decline of beneficial insects and pollinators (Hallmann et al., 2017), scientific knowledge about the effects of mixtures of pesticides with different modes of action remains very limited.

The effects of mixtures of pesticide residues is even less known for non-target soil organisms. Some studies have raised concerns about the effects of cocktails of pesticides on earthworms by reporting, among others, avoidance behaviour (Pereira et al., 2009), DNA damage (Uwizeyimana et al., 2017), and changes in enzymatic activities (Jouni et al., 2020; Tiwari et al., 2016). Pesticides are also known to have various effects on the soil microbiome (Oyeleke et al., 2011; Wang et al., 2020) with various microorganisms being negatively impacted while others thrive leading sometimes to an imbalance between beneficial and pathogenic microorganisms (Van Bruggen et al., 2018). Earthworms and microorganisms play a key role in soil fertility but the consequences of multiple pesticides contaminating soil remains uncertain. Kosubová et al. (2020) recently suggested a more integrated method for assessing risks in the soil ecosystem.

Considering the high persistence of certain pesticides, including the long-banned organochlorine pesticides like DDT, soil assessments are pertinent not only to conventional farms but also to organic farms. In fact, farms that have converted to organic farming within the last $2-3$ years can exhibit contamination by pesticides applied while managed conventionally. This can occur because the required $2-3$ year transition time for converting to organic farming may not be enough for the complete decay of some residues (EC, 2008b). Furthermore, drift and atmospheric deposition from nearby conventional farms may also contribute to organic soil contamination. Soil contamination assessments are particularly relevant since organic farming areas are rapidly developing in the European Union (EU) in response to higher consumer concerns regarding food and environmental safety, new Farm to Fork policy and financial support for organic production (Willer and Lernoud, 2019; EC, 2020a).

Most pesticides are applied during the crops' growing season, resulting in a peak of residues in soils during this period. However, residues may persist long after application, and accumulate in soil over the years. Pesticide mixtures in soils are usually only evaluated at the case study level (vs. large scale assessments) due to the high analytical costs and the lack of a mandatory post-approval pesticide monitoring system. Silva et al. (2019) provided the first study with a more comprehensive overview of EU soil status, analysing 76 pesticide residues in 317 agricultural samples from 11 EU countries. They identified 166 different pesticide mixtures, with a maximum of 13 residues (active substances and metabolites) per soil sample. However, we don't know if these findings were a result of shortterm contamination or accumulated residues and we don't know which farm management system the results relate to.

The Regulation (EC) No 1107/2009 on the placing of pesticides on the market has acted as a catalyst for the development of more accurate exposure modelling tools and risk-evaluation procedures (EC, 2009a). Actual risk assessment procedures from EFSA are performed based on Toxicity Exposure Ratios (TERs) of single residues in which predicted environmental concentrations of pesticides in soil (PECs) are used as an exposure proxy for soil organisms. These PECs are calculated based on representative pesticide uses and recommended application schemes. A validation of the PECs with field data has not been conducted yet, including predictions for different soils and climatic characteristics. Furthermore, historical contamination due to banned and discontinued pesticides is not considered in the pesticide approval process, which may lead to an underestimation of the real risk. Knowing which pesticide mixtures exist in soil is a pre-requisite to realistic assessments of pesticide impacts on soil organisms, as well as comprehensive pesticide risk assessments.

The main objectives of this study were to (i) compare the pesticide residue mixtures present in topsoils of organic and conventional farms in different regions of Europe, and (ii) discuss the (need for) regulations related to residue mixtures in soils and for transitioning to organic farming. With this study, we have gained knowledge that will assist in the implementation of the European Green deal, namely the recently published Farm to Fork Strategy and the Zero Pollution Strategy that aim to reduce pesticide use by $50 \%$, eliminate soil pollution and establish a minimum of $25 \%$ organic farmland in Europe by 2030 (EC, 2020a; 2020b).

\section{Methodology}

\subsection{Case study sites overview}

For this study, we compiled data collected from 4 Case Study Sites (CSS; Fig. 1; Table 1) from 3 EC funded projects addressing soil quality: RECARE (www.recare-project.eu/), iSQAPER (www. isqaper-project.eu) and DIVERFARMING (www.diverfarming.eu/). In all three projects, pesticide application patterns and distribution of pesticide residues in agricultural soils were studied at a CSS level. These CSS represented typical cropping systems and covered different climate zones: vegetable production under plastic mulch in Southeast-Spain $(\mathrm{S}-\mathrm{V})$, orange production in Eastern Spain $(\mathrm{S}-\mathrm{O})$, grape production in Northern Portugal $(\mathrm{P}-\mathrm{G})$, and potato production in Northern Netherlands $(\mathrm{N}-\mathrm{P})$. The CSS included both organic and conventional production systems, except for $\mathrm{P}-\mathrm{G}$ (organic grape farms were not common in the sampled area of Portugal). The organic fields were converted more than 5 years ago $(\mathrm{S}-\mathrm{V}, \mathrm{S}-\mathrm{O})$ or more than 10 years ago $(\mathrm{N}-\mathrm{P})$. The conventional farms were managed as such for at least the last 10 years. Overall, we collected and analysed 340 topsoil samples (0-10/15 cm depth). Soil samples were collected between 2015 and 2018 at the end of the growing season $(\mathrm{S}-\mathrm{V}, \mathrm{S}-\mathrm{O}, \mathrm{P}-\mathrm{G}$ ) or before the growing season $(\mathrm{N}-\mathrm{P})$. Sampling at the end of the growing season aimed to assess the accumulative soil contamination scenario after the application period (expected to be the worst-case scenario) while sampling before the growing season tested the background situation. The characteristics of the CSS and the sampling pattern for each CSS are presented in Table 1. The soil samples were air-dried (at ambient temperatures, under dark conditions, and for a maximum of 1 week), sieved to $2 \mathrm{~mm}$ and frozen $\left(-20^{\circ} \mathrm{C}\right)$ until the extraction and determination of pesticide residues could be carried out. 


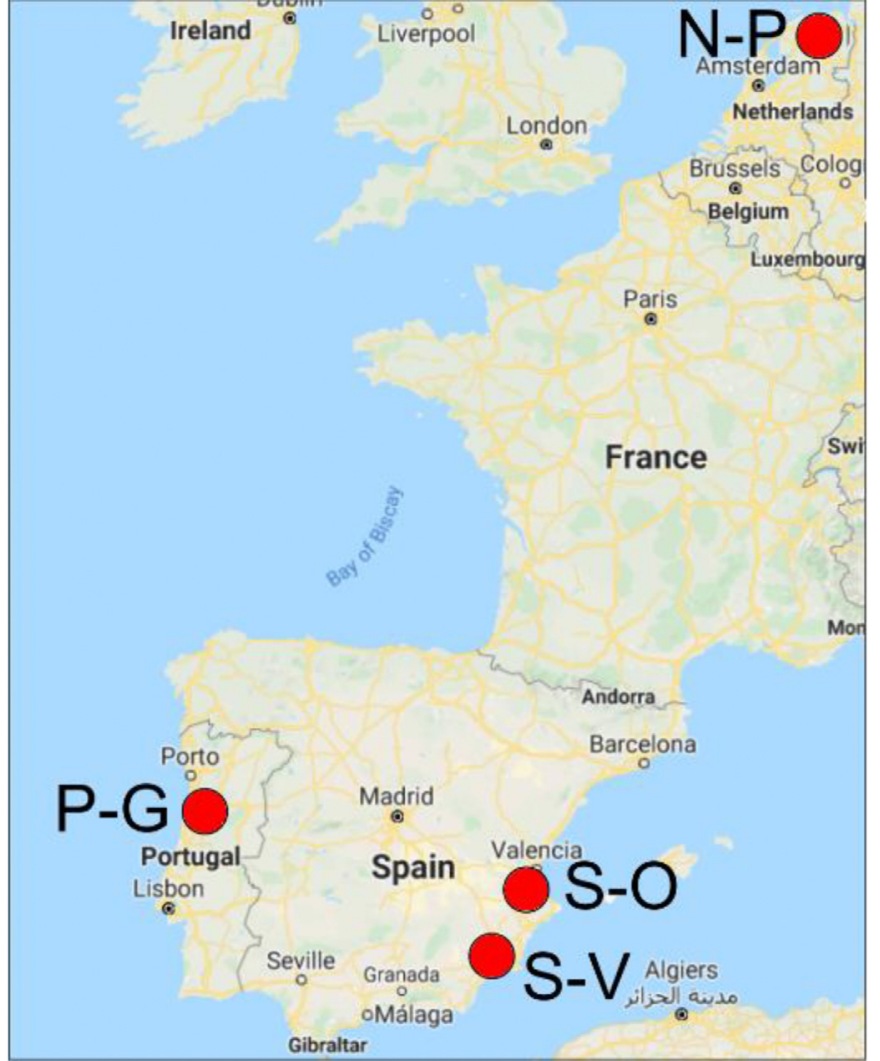

Fig. 1. Map of the locations of the different Case Study Sites (CSS; see Table 1 for the description of the CSS characteristics). $\mathrm{S}-\mathrm{V}=$ vegetables production in SoutheastSpain, $\mathrm{S}-\mathrm{O}=$ orange production in Eastern Spain, $\mathrm{P}-\mathrm{G}=$ grape production in Northern Portugal, and $\mathrm{N}-\mathrm{P}=$ potato production in Northern Netherlands.

\subsection{Selection of the pesticide residues to be analysed}

For each CSS, we carried out interviews with farmers and pesticide retailers and asked which pesticides had been used on the farms during the 2 growing seasons prior to sampling. Interview questions covered the type of substances applied, the application amounts, and the application timing. The results of the interviews are presented in Table S1. As we depended upon the willingness of the farmers and retailers to answer the questions, different information was gathered across the study sites:

a) In $\mathrm{P}-\mathrm{G}$, all the 9 farmers ( 9 conventional) replied, giving a short list of pesticides used. Detailed application records from 5 of these farmers were later made available to us.

b) In $\mathrm{N}-\mathrm{P}, 10$ of the potato farmers ( 9 conventional and 1 organic) replied, and detailed pesticide application records were gathered from them.

c) In $S-V$, all the conventional farmers (6) gave the names of applied pesticides. Detailed application records from 3 of these farmers were later made available to us.

d) In $\mathrm{S}-\mathrm{O}, 4$ of the farmers (3 conventional and 1 organic) and one pesticide retailer replied, but only the names of the applied pesticides were made available.

The information obtained from the interviews was combined with EUROSTAT data of the most common pesticides used in our crop-country combinations (EUROSTAT, 2017) in order to define a list of analytes of high interest per CSS. Additionally, in $\mathrm{S}-\mathrm{O}, \mathrm{P}-\mathrm{G}$ and $\mathrm{N}-\mathrm{P}$, we analysed obsolete pesticide residues, such as

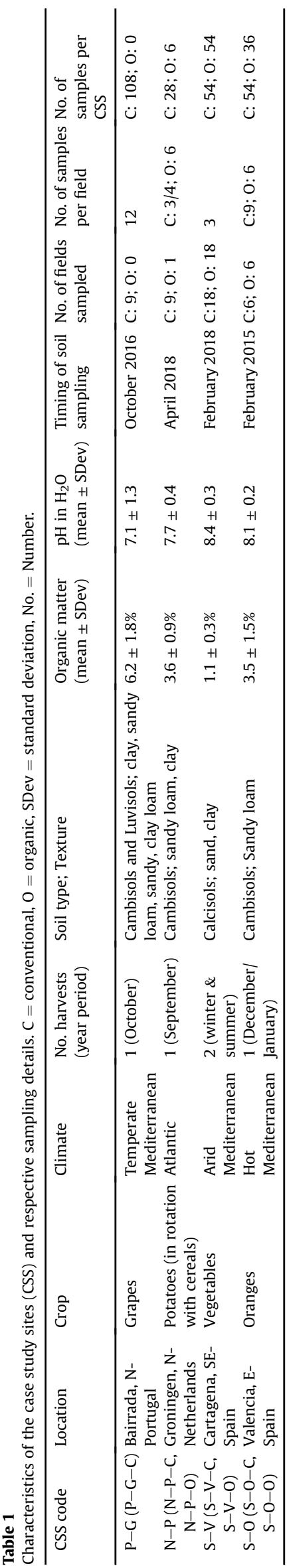


organochlorides and organophosphates that were banned decades ago, in order to gain insight on long-term soil contamination. The main metabolites of currently used and obsolete pesticides were also added to the list of analytes of high interest (details see Table S1). The residues that required a specific analytical method (with the exception of glyphosate and its main metabolite AMPA), or that did not present satisfactory recoveries (between 80 and $120 \%$ ) during the validation step of the multi-residue method were excluded. The final list of analytes (i.e. the list of the pesticide residues tested in soil samples) included 47 residues in $P-G, 36$ in $\mathrm{N}-\mathrm{P}, 38$ in $\mathrm{S}-\mathrm{V}$ and 75 in $\mathrm{S}-\mathrm{O}$. Overall, 151 different pesticide residues were tested: 66 approved active substances, 70 nonapproved active substances and 15 metabolites (Table S2). In this study we focused only on synthetic pesticide residues.

\subsection{Analysis of pesticide residues in soil samples}

All soil samples were thawed and homogenised (hand mixed until a visual homogeneous sample was obtained) and split into two aliquots: one for the determination of basic soil properties $(\mathrm{pH}$, organic matter and texture) and one for determination of pesticide residues. The pesticide residue aliquot was also split into two parts: $2 \mathrm{~g}$ for the determination of glyphosate and its main metabolite AMPA (in $\mathrm{S}-\mathrm{O}, \mathrm{P}-\mathrm{G}$ and $\mathrm{N}-\mathrm{P}$ ) and the remaining $5 \mathrm{~g}$ for the screening of multi-residues (all CSS). Since none of the parties interviewed for this study reported that glyphosate was applied in $\mathrm{S}-\mathrm{V}$, it was not analysed in those samples. Glyphosate and AMPA were determined using the method described by Bento et al. (2016) and Yang et al. (2015) using LC-MS/MS (liquid chromatographytandem mass spectrometry; Instrument: Quattro Ultima from Micromass (UK) coupled to a Acquity UPLC system from Waters (USA). The other pesticide residues were extracted using an adaptation of the QuEChERS approach to soil samples, as described by Silva et al. (2019) and analysed by LC-MS/MS (different MS systems: Quattro Ultima from Micromass, Premier, TQ-S and TQ-XS from Waters, all coupled to Acquity UPLC systems from Waters) and GCMS/MS (gas chromatography-tandem mass spectrometry; Instruments: 300 GC-MS from Bruker, and a 7010B MS coupled to a 7890B GC from Agilent Technologies) or GC-HRMS (gas chromatography-high-resolution mass spectrometry; Instrument: Q-Exactive GC Orbitrap from Thermo Scientific).

Analyses were performed according to the analytical quality control and method validation procedures for pesticides residues analysis in food and feed. The guidelines for the current version, at the time of analysis, of the SANTE document were applied (EC 2015; 2017). Analyses involved the use of calibration standards, reference standards, isotope labelled internal standards, a surrogate standard (caffeine) and of an injection standard (PCB-198). The calibration standards were prepared from a mix solution that combined the reference standards of all the compounds that were going to be analysed. Isotope labelled internal standards were only used in glyphosate and AMPA determinations, for normalization of response of these compounds. Caffeine was used as a surrogate to check potential issues in the in LC-MS/MS analyses other than glyphosate and AMPA, and PCB-198 for normalization of response in the GC-MS/MS and GC-HRMS analyses. Further details on standards can be found in Silva et al. (2019). The reference standards were purchased from LGC Standards (Germany), HPC Standards (Germany) or Sigma-Aldrich (USA). The isotope labelled internal standards of glyphosate and AMPA and the PCB-198 were obtained from LGC Standards (Germany) while the caffeine was purchased from Sigma-Aldrich (USA). Limits of quantification (LoQ) were used as reporting limits. The LoQ of glyphosate and AMPA was $0.050 \mathrm{mg} \mathrm{kg}^{-1}$ while the LoQ of the remaining residues ranged between 0.001 and $0.02 \mathrm{mg} \mathrm{kg}^{-1}$ (Table S2).

\subsection{Data analysis}

\subsubsection{Interviews}

All data (interviews, sampling) were collected using different sampling patterns due to the requirements of the different European projects associated with each CSS. We did not conduct statistical tests on the data derived from interviews due the fact that the interviews only resulted in a limited amount of information. However, we used the data from the interviews to give a realistic qualitative overview about the pesticide applications and resulting accumulated residues in soils under different cropping and farming systems. The number and basic characteristics of the active substances identified in the farmers' interviews are presented in Table S1. When pesticide application rates were available, they were included in the table; when application rates were not available, the substance was listed in the table with no associated application amount.

\subsubsection{Residues in soil}

We calculated the frequency of detection, the median and the range of concentrations for each compound from each organic and conventional farming system per CSS. The pesticide residues with the highest frequencies $(\geq 50 \%)$ and with moderate frequencies in soils (20-50\%) are presented in Table 3. Data from pesticide residues with frequencies below $20 \%$ are shown in Table S3. Furthermore, we present the range and the median number of pesticide residues found in organic and conventional soils for each CSS. We added the content of the different pesticide residues found in each sample to obtain the total residues content per sample. Nonparametric Mann Whitney U tests were used to test significant differences in the number of residues and in the total residues content in soils between conventional and organic farms within the same CSS, and between CSS within the same farming strategy. Statistical analyses were performed using STATISTICA, version 12 . The significance level was set at 0.05 .

\section{Results}

\subsection{Applications of pesticides in the CSS}

The number of applied pesticides (active substances) varied strongly across conventional farms, and across the CSS (Fig. 2; Table S1). Overall, farmers reported 98 active substances: 69 active substances were applied in only one CSS, 19 active substances were applied in two CSS, and 9 active substances ( 8 fungicides and 1 insecticide) were applied in three CSS. The compound with highest input was the insecticide chlorantraniliprole, with around $35 \mathrm{~kg} \mathrm{ha}^{-1}$ year $^{-1}$ in S-V-C (Table S1). A maximum of 11 different active substances were applied per farm per year in $\mathrm{S}-\mathrm{O}-\mathrm{C}$, between 10 and 18 active substances in $P-G-C$ farms, between 8 and 22 active substances in $\mathrm{S}-\mathrm{V}-\mathrm{C}$ farms, and finally, between 5 and 44 active substances in $\mathrm{N}-\mathrm{P}-\mathrm{C}$ farms (Fig. 2). In $\mathrm{N}-\mathrm{P}-\mathrm{C}$, farmers applied mainly herbicides, in $\mathrm{P}-\mathrm{G}$ and $\mathrm{S}-\mathrm{V}-\mathrm{C}$ mainly fungicides, and in $\mathrm{S}-\mathrm{O}-\mathrm{C}$ mainly insecticides. $44-55 \%$ of the active substances applied in the CSS are non-persistent, 26-36\% moderately persistent, $0-24 \%$ persistent and $4-11 \%$ very persistent (Table 2 ).

\subsection{Pesticide residues identified in the CSS}

\subsubsection{Frequency of detection}

The number of residues found in EU soil samples ranged between 0 and 16 , with significantly more residues discovered in conventional fields than in organic fields (Fig. 3). The only pesticide residue-free soils under conventional farming were identified in $\mathrm{S}-\mathrm{O}-\mathrm{C}$ ( $2 \%$ of all conventional soils; Fig. 4$)$; all other soils under 


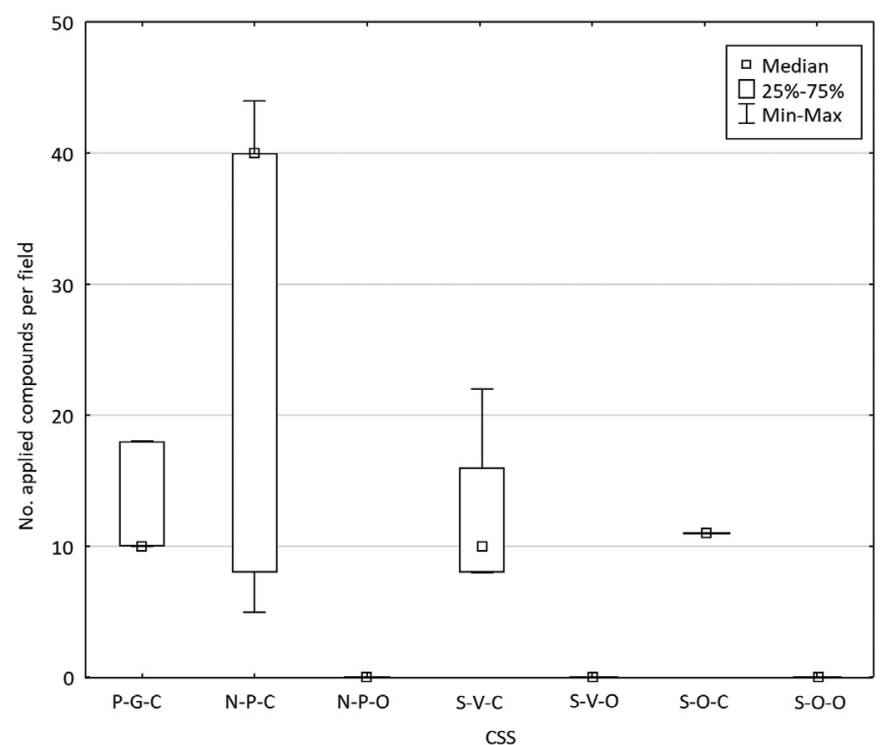

Fig. 2. Number of active substances applied per field per year in the different Case Study Sites (CSS). Data based on interviews with farmers and pesticide retailers. Min = minimum; Max = maximum. Vegetable production in Southeast-Spain $(\mathrm{S}-\mathrm{V})$, orange production in Eastern Spain $(\mathrm{S}-\mathrm{O})$, grape production in Northern Portugal $(\mathrm{P}-\mathrm{G})$, and potato production in Northern Netherlands $(\mathrm{N}-\mathrm{P}) . \mathrm{C}=$ conventional; $\mathrm{O}=$ organic, No. $=$ number.

conventional farming contained one or more pesticide residues. In P-G-C and S-O-C, more than $80 \%$ of the soils contained 2 to 5 residues, while most $\mathrm{N}-\mathrm{P}-\mathrm{C}$ and $\mathrm{S}-\mathrm{V}-\mathrm{C}$ samples contained 6 to 10 different residues (71\% and $83 \%$, respectively). A substantial part of $\mathrm{N}-\mathrm{P}-\mathrm{C}(25 \%)$ and $\mathrm{S}-\mathrm{V}-\mathrm{C}(9 \%)$ soil samples contained even more complex mixtures, with more than 10 residues. As mentioned above, soils from organic farms contained significantly fewer residues, with $44 \%$ of the soils in $\mathrm{S}-\mathrm{V}-\mathrm{O}$ and $11 \%$ of the soils in $\mathrm{S}-\mathrm{O}-\mathrm{O}$ being free of tested pesticide residues. However, $100 \%$ of $\mathrm{N}-\mathrm{P}-\mathrm{O}$ soils and $72 \%$ of $\mathrm{S}-\mathrm{O}-\mathrm{O}$ of the soils contained mixtures of $2-5$ residues. In $\mathrm{S}-\mathrm{V}-\mathrm{O}, 30 \%$ of the soil samples contained 1 residue and $26 \%$ of the samples contained 2 to 5 residues (Fig. 4).

The highest number of residues per sample were found in $\mathrm{N}-\mathrm{P}-\mathrm{C}$. If only median values are considered, the number of residues found in soil decreased according to the following order: $\mathrm{N}-\mathrm{P}-\mathrm{C}>\mathrm{S}-\mathrm{V}-\mathrm{C}>\mathrm{P}-\mathrm{G}-\mathrm{C}>\mathrm{S}-\mathrm{O}-\mathrm{C}$ (Fig. 3). In total, 15 residues were detected with a frequency above $50 \%$ in one or more of the CSS and 7 residues with a frequency between 20 and $50 \%$ in one or more of the CSS (Table 3). The group of 15 residues with a frequency $\geq 50 \%$ included 3 very persistent (VP) residues, 7 persistent $(\mathrm{P})$ residues, 4 moderately persistent (MP) residues, and 1 nonpersistent residue (NP). This group included 1 banned organochlorine pesticide. 8 out of the 15 more common residues were fungicides, 4 were herbicides, and 3 were insecticides. From the 7

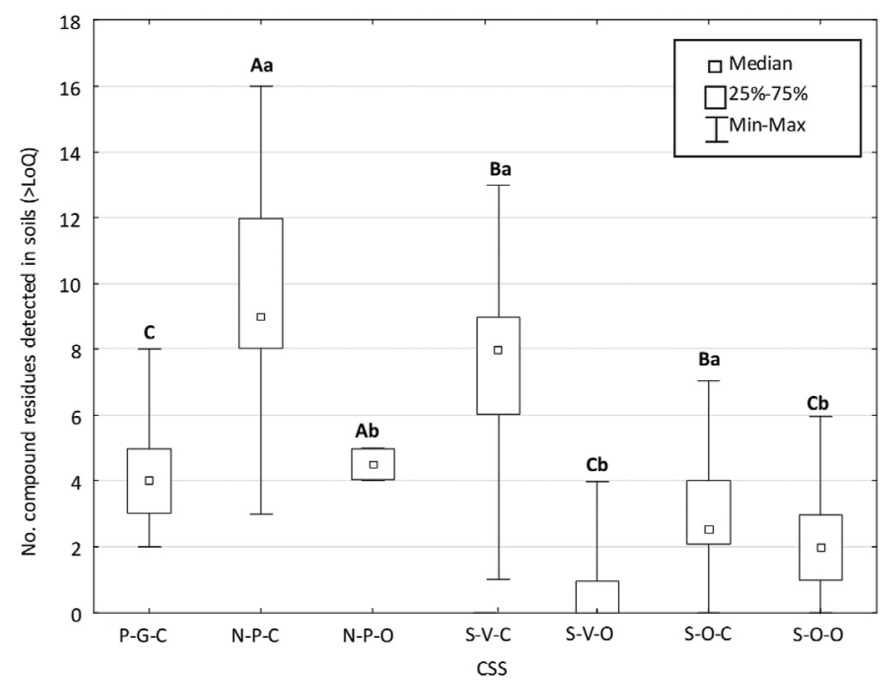

Fig. 3. Numbers of pesticide residues identified per soil sample across Case Study Sites, CSS. Significant differences among CSS within the same management system (Mann and Whitney $U$ Test, $\mathrm{p}<0.05): \mathrm{A}>\mathrm{B}>\mathrm{C}$. Significant differences between organic and conventional fields, from the same CSS: $a>b$. Number of samples, $n: P-G-C n: 108$, N-P-C n: 28, N-P-O n: 6, S-V-O n: 54, S-V-C n: 54, S-O-O n: 36, S-O-C n: 54. Vegetable production in Southeast-Spain $(\mathrm{S}-\mathrm{V})$, orange production in Eastern Spain $(\mathrm{S}-\mathrm{O})$, grape production in Northern Portugal $(\mathrm{P}-\mathrm{G})$, and potato production in Northern Netherlands $(\mathrm{N}-\mathrm{P}) . \mathrm{C}=$ conventional; $\mathrm{O}=$ organic, No. = number, LoQ - Limit of quantification.

residues with a frequency of 20-50\%, 4 were VP, 2 P and 1 MP; 4 were fungicides and 3 were insecticides ( 2 of them banned, DDT metabolites). From the residues with moderate-high detection frequencies ( $>20 \%$, Table 3 ), only $46 \%$ were reported to be applied.

In $\mathrm{P}-\mathrm{G}-\mathrm{C}$, the number of pesticide residues in soil ranged from 2 to 8 , with a median of 4 residues per soil sample (Fig. 3). $26 \%$ of the applied compounds in $\mathrm{P}-\mathrm{G}$ site were detected as residues in soil. None of the banned pesticides tested were detected in the $\mathrm{P}-\mathrm{G}-\mathrm{C}$ samples (Table 3, Table S3). Four compounds were detected with a frequency $>50 \%$ : AMPA $(83 \%)$ and glyphosate $(78 \%)$ and the fungicides metalaxyl (51\%) and dimethomorph (100\%). Three other compounds, all fungicides, were detected with a frequency between 20 and 50\%: penconazole, tebuconazole and pyraclostrobin (Fig. 4, Table 3).

In $\mathrm{N}-\mathrm{P}-\mathrm{C}, 3$ to 16 residues were found with a median of 9 residues per soil sample. In the organically-managed fields in $\mathrm{N}-\mathrm{P}-\mathrm{O}$, a median of 5 residues/sample was identified although no pesticides had been reportedly applied in the past 10 years (Fig. 3). $17 \%$ of the applied compounds were detected as residues in the soils. In $\mathrm{N}-\mathrm{P}-\mathrm{C}, 6$ compounds were present with an overall frequency $>50 \%$ ( 3 fungicides, 2 herbicides, 1 obsolete insecticide) and 2 compounds were detected with a frequency between 20 and $50 \%$ : bixafen, a VP fungicide, and an obsolete insecticide (Table 3). In

Table 2

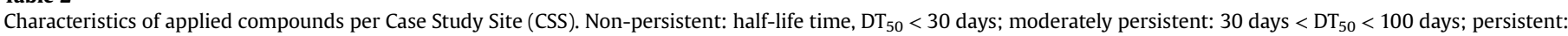

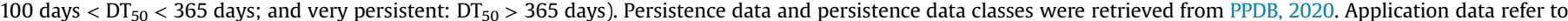

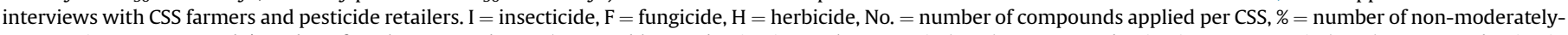

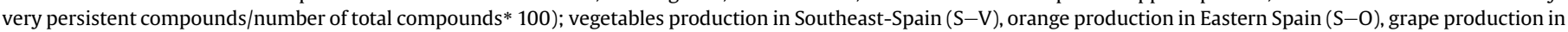
Northern Portugal (P-G), and potato production in Northern Netherlands $(\mathrm{N}-\mathrm{P}), \mathrm{C}=$ conventional, $\mathrm{O}=$ organic. Percentages were rounded to the unit.

\begin{tabular}{|c|c|c|c|c|c|}
\hline CSS code & Total No. of compounds applied & $\begin{array}{l}\text { Non- persistent } \\
\text { compounds No./\% }\end{array}$ & $\begin{array}{l}\text { Moderately persistent } \\
\text { compounds No. } \%\end{array}$ & $\begin{array}{l}\text { Persistent } \\
\text { compounds No./\% }\end{array}$ & $\begin{array}{l}\text { Very persistent } \\
\text { compounds No./\% }\end{array}$ \\
\hline $\mathrm{P}-\mathrm{G}-\mathrm{C}$ & $18(\mathrm{I}: 2, \mathrm{~F}: 15, \mathrm{H}: 1)$ & $8 / 44 \%$ & $6 / 33 \%$ & $2 / 11 \%$ & $2 / 11 \%$ \\
\hline $\mathrm{N}-\mathrm{P}-\mathrm{C}$ & 57 (I:10, F:19, H:28) & $25 / 44 \%$ & $18 / 32 \%$ & $11 / 19 \%$ & $3 / 5 \%$ \\
\hline $\mathrm{S}-\mathrm{V}-\mathrm{C}$ & $50(\mathrm{I}: 19, \mathrm{~F}: 22, \mathrm{H}: 9)$ & $23 / 46 \%$ & $13 / 26 \%$ & $12 / 24 \%$ & $2 / 4 \%$ \\
\hline $\mathrm{S}-\mathrm{O}-\mathrm{C}$ & 11 (I:5, F:3, H:3) & $6 / 55 \%$ & $4 / 36 \%$ & $0 / 0 \%$ & $1 / 9 \%$ \\
\hline
\end{tabular}




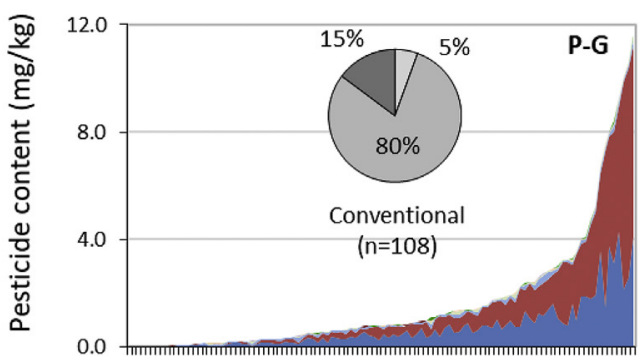

\begin{tabular}{|c|c|}
\hline \multirow{2}{*}{$\begin{array}{l}\text { Pie charts } \\
\text { Percentage of samples: }\end{array}$} & \multirow{2}{*}{$\frac{\text { Compounds }}{\text { AMPA }}$} \\
\hline & \\
\hline No residues & \\
\hline 1 residue & Bixafen \\
\hline 2-5 residues & Boscalid \\
\hline $6-10$ residues & Chlorantraniliprole \\
\hline$>10$ residues & DDTs \\
\hline & Difenoconazole \\
\hline & Dimethomorph \\
\hline
\end{tabular}

Fluopicolide Glyphosate Imidacloprid Indoxacarb Linuron Metalaxyl Metamitron Metrafenone
Others Oxyfluorfen Penconazole Pendimethalin Prochloraz Prosulfocarb Pyraclostrobin Tebuconazole

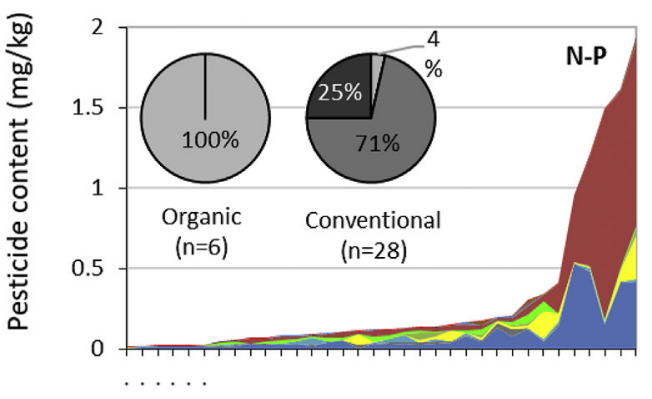

Samples

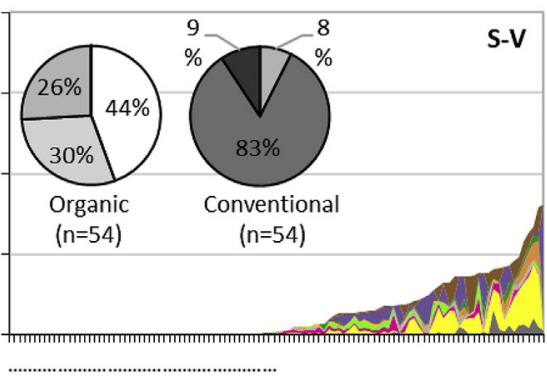

Samples

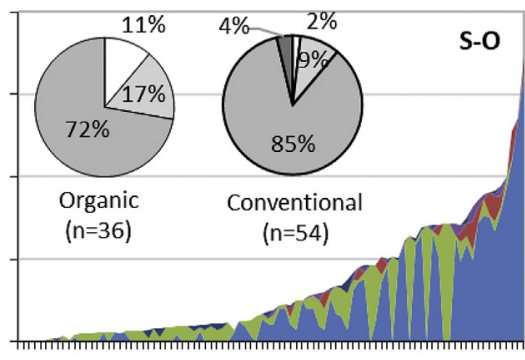

Samples

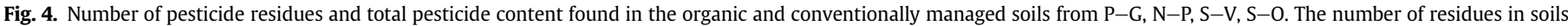

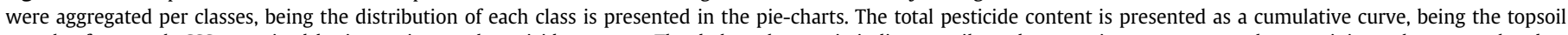

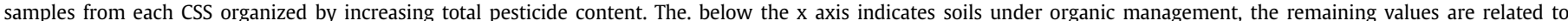

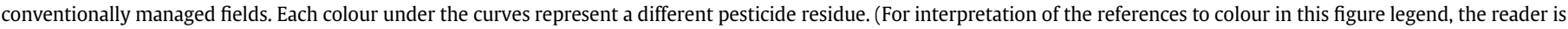
referred to the Web version of this article.)

Table 3

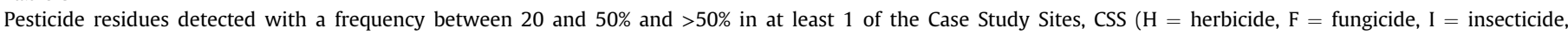

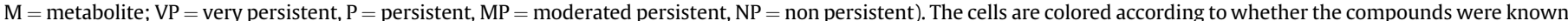

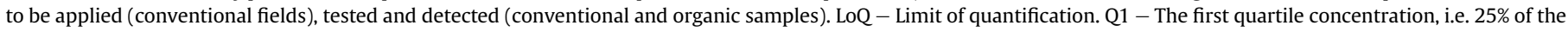

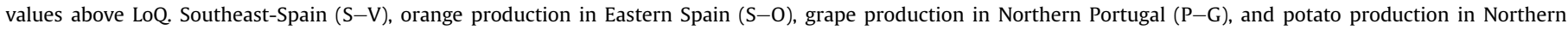
Netherlands $(\mathrm{N}-\mathrm{P})$, conv $=$ conventional, org $=$ organic.

\begin{tabular}{|c|c|c|c|c|c|c|c|c|c|c|c|c|c|c|c|c|c|c|}
\hline & \multirow[b]{2}{*}{ Compound } & \multirow[b]{2}{*}{ Persistence } & \multicolumn{4}{|c|}{ P-G (conv) } & \multicolumn{4}{|c|}{ N-P (conv/org) } & \multicolumn{4}{|c|}{ S-V (conv/org) } & \multicolumn{4}{|c|}{ S-O (conv/org) } \\
\hline & & & $\%$ freq & Q1 & $\operatorname{Max}$ & Median & $\%$ freq & Q1 & $\operatorname{Max}$ & Median & $\%$ freq & Q1 & Max & Median & $\%$ freq & Q1 & $\operatorname{Max}$ & Median \\
\hline \multirow{15}{*}{$\begin{array}{l}>50 \% \\
\text { frequency }\end{array}$} & AMPA (M-H) & $\mathrm{VP}$ & 83 & 0.260 & 4.294 & 0.505 & $96 / 83$ & $0.026 / 0.012$ & $0.528 / 0.014$ & $0.037 / 0.013$ & & & & & $87 / 17$ & $0.102 / 0.069$ & $1.626 / 0.593$ & $0.261 / 0.070$ \\
\hline & Azoxystrobin (F) & $\mathrm{NP}$ & 4 & 0.014 & 0.022 & 0.019 & $0 / 0$ & $<$ LoQ/ $<$ LoQ & $<L O Q /<L O Q$ & $<L \circ O /<L O Q$ & $72 / 0$ & $0.005 /<$ LoQ & $0.153 /<$ LoQ & $0.009 /<\operatorname{LOQ}$ & & & & \\
\hline & Boscalid (F) & $\mathrm{VP}$ & & & & & $39 / 0$ & $0.015 /<$ LoQ & $0.520 /<\mathrm{LOQ}$ & $0.270 /<\operatorname{LOQ}$ & $85 / 0$ & $0.011 /<$ LoQ & $0.330 /<\mathrm{LoQ}$ & $0.055 /<\operatorname{LoQ}$ & & & & \\
\hline & Chlorantranilprole (I) & $\mathrm{P}$ & & & & & & & & & $100 / 7$ & $0.010 / 0.001$ & $0.101 / 0.001$ & $0.017 / 0.001$ & & & & \\
\hline & DDE pp (I) & $\mathrm{VP}$ & 0 & $<L O Q$ & $<L O Q$ & $<L O Q$ & $11 / 0$ & $0.010 /<L \mathrm{LQ}$ & $0.030 /<\mathrm{LOQ}$ & $0.017 /<\operatorname{LOQ}$ & & & & & $78 / 89$ & $0.016 / 0.045$ & $0.161 / 0.570$ & $0.031 / 0.080$ \\
\hline & \begin{tabular}{|l} 
Difenoconazole (F) \\
\end{tabular} & $P$ & & & & & & & & & $65 / 17$ & $0.006 / 0.001$ & $0.062 / 0.001$ & \begin{tabular}{|l|}
$0.019 / 0.001$ \\
\end{tabular} & & & & \\
\hline & \begin{tabular}{|l} 
Dimethomorph (F) \\
\end{tabular} & MP & 100 & 0.029 & 0.301 & 0.056 & & & & & $24 / 0$ & $0.001 /<$ LoQ & $0.011 /<$ LoQ & $0.003 /<$ LoQ & & & & \\
\hline & Fluopicolide (F) & $P$ & & & & & $61 / 0$ & $0.016 /<$ LoQ & $0.061 /<$ LoQ & $0.018 /<$ LoQ & $48 / 0$ & $0.009 /<$ LOQ & $0.096 /<$ LoQ & $0.024 /<$ LoQ & & & & \\
\hline & Glyphosate $(\mathrm{H})$ & $P$ & 78 & 0.179 & 7.843 & 0.452 & $93 / 0$ & $0.018 /<\operatorname{LOQ}$ & $1.300 /<\mathrm{LoQ}$ & $0.029 /<\operatorname{LoQ}$ & & & & & $22 / 6$ & $0.070 / 0.076$ & $0.180 / 0.105$ & $0.090 / 0.090$ \\
\hline & \begin{tabular}{|l} 
Imidacloprid (I) \\
\end{tabular} & $P$ & & & & & & & & & $93 / 30$ & $0.002 / 0.001$ & $0.163 / 0.002$ & $0.004 / 0.001$ & & & & \\
\hline & Metrafenone (F) & $\mathrm{P}$ & & & & & & & & & $56 / 0$ & $0.006 /<$ LoQ & $0.021 /<\operatorname{LoQ}$ & $0.009 /<$ LoQ & & & & \\
\hline & Metalaxyl (F) & MP & 51 & 0.017 & 0.173 & 0.034 & & & & & $0 / 0$ & $<L \circ Q /<L O Q$ & $<L \circ Q /<L O Q$ & $<L \circ Q /<L O Q$ & $0 / 0$ & $<\llcorner\circ Q /<L O Q$ & $<L \circ Q /<L \circ Q$ & $<L \circ Q /<L O Q$ \\
\hline & Oxyfluorfen (H) & MP & & & & & & & & & $70 / 0$ & $0.009 /<$ LoQ & $0.605 /<$ LoQ & $0.051 /<\operatorname{LoQ}$ & $37 / 0$ & $0.016 /<$ LoQ & $0.085 /<$ LoQ & $0.023 /<\operatorname{LoQ}$ \\
\hline & \begin{tabular}{|l} 
Pendimethalin $(\mathrm{H})$ \\
\end{tabular} & $P$ & & & & & $11 / 0$ & $0.019 /<$ LoQ & $0.023 /<$ LoQ & $0.019 /<$ LoQ & $63 / 0$ & $0.007 /<$ LoQ & $0.234 /<$ LoQ & $0.032 /<\operatorname{LoQ}$ & & & & \\
\hline & Pyraclostrobin (F) & MP & 32 & 0.018 & 0.058 & 0.029 & & & & & $56 / 0$ & $0.002 /<$ LoQ & $0.034 /<\mathrm{LoQ}$ & $0.003 /<$ LoQ & & & & \\
\hline \multirow{7}{*}{$\begin{array}{l}20-50 \% \\
\text { frequency }\end{array}$} & Bixafen (F) & $\mathrm{VP}$ & & & & & $46 / 0$ & $0.011 /<\angle 0 Q$ & $0.049 /<\mathrm{LOQ}$ & $0.013 /<$ LOQ & & & & & & & & \\
\hline & DDD pp (I) & VP & 0 & $<L O Q$ & $<L O Q$ & $<L O Q$ & $0 / 0$ & $<\mathrm{LOQ} /<\mathrm{LOQ}$ & $<\angle O Q /<L O Q$ & $<L O Q /<L O Q$ & & & & & $13 / 44$ & $0.011 / 0.014$ & $0.032 / 0.071$ & $0.017 / 0.017$ \\
\hline & DDT pp (I) & $\mathrm{VP}$ & 0 & $<\angle O Q$ & $<L O Q$ & $<L O Q$ & $14 / 0$ & $0.010 /<$ LoQ & $0.020 /<$ LoQ & $0.012 /<$ LoQ & & & & & $19 / 46$ & $0.013 / 0.014$ & $0.026 / 0.089$ & $0.016 / 0.021$ \\
\hline & Indoxacarb (I) & $\mathrm{P}$ & & & & & & & & & $33 / 0$ & $0.001 /<$ LoQ & $0.022 /<L \mathrm{LQ}$ & $0.001 /<$ LoQ & & & & \\
\hline & Penconazole (F) & $\mathrm{P}$ & 17 & 0.012 & 0.049 & 0.021 & & & & & & & & & & & & \\
\hline & Prochloraz (F) & $\mathrm{VP}$ & & & & & & & & & & & & & $33 / 17$ & $0.012 / 0.028$ & $0.054 / 0.083$ & $0.013 / 0.033$ \\
\hline & Tebuconazole (F) & MP & 16 & 0.010 & 0.096 & 0.011 & $0 / 0$ & $<\mathrm{LOQ} /<\mathrm{LOQ}$ & $<L O Q /<L O Q$ & $<\mathrm{LoQ} /<\mathrm{LoQ}$ & & & & & & & & \\
\hline
\end{tabular}

legend:

\begin{tabular}{|l|l}
\hline known to be applied but not detected & known to be applied and detected
\end{tabular}

known to be applied but not tested $\quad$ obsolete pesticide and not detected $\quad$ known to be not applied but detected $\quad$ not applied and not tested

$\mathrm{N}-\mathrm{P}-\mathrm{O}$, only 1 compound (AMPA, a VP herbicide metabolite) was identified with a frequency $>50 \%$. The glyphosate metabolite AMPA was the most frequent residue found in both conventional and organic fields, with a frequency of 96 and $83 \%$, respectively. The metabolites of the banned insecticide DDT were also identified in soils under both conventional and organic farming (Table 3). The fungicides boscalid, bixafen and fluopicolide as well as the herbicide glyphosate were detected with frequencies $>50 \%$ in $\mathrm{N}-\mathrm{P}-\mathrm{C}$, but were not present in $\mathrm{N}-\mathrm{P}-\mathrm{O}$.

In $\mathrm{S}-\mathrm{V}-\mathrm{C}$, the number of positively quantified residues ranged 
from 1 to 13 , with a median of 8 compounds per soil sample. In $\mathrm{S}-\mathrm{V}-\mathrm{O}$ samples, a maximum of 4 residues was detected in a unique soil sample (Fig. 3). $47 \%$ of the applied compounds in this CSS were detected as residues in the soils. In $\mathrm{S}-\mathrm{V}-\mathrm{C}, 9$ compounds ( 2 herbicides, 5 fungicides and 2 insecticides) were detected with a frequency $>50 \%$ and 3 (2 F, 1 I) with a frequency between 20 and $50 \%$. The 9 different residues consisted of $2 \mathrm{NP}, 5 \mathrm{MP}, 4 \mathrm{P}$ and $2 \mathrm{~V}$ P. The compounds occurring with the highest frequency were the insecticides chlorantraniliprole (100\%) and imidacloprid (92\%). The herbicide pendimethalin was detected with a frequency of $63 \%$. In $\mathrm{S}-\mathrm{V}-\mathrm{O}$, only the persistent insecticide Imidacloprid occurred with a frequency $>20 \%$.

In $\mathrm{S}-\mathrm{O}-\mathrm{C}$, the number of quantified residues ranged from 0 to 7 , with a median of 2 residues per sample. In $\mathrm{S}-\mathrm{O}-\mathrm{O}$ samples, a maximum of 6 residues was detected (Fig. 3). 18\% of the applied compounds were detected in soil. In $\mathrm{S}-\mathrm{O}-\mathrm{C}$, the very persistent metabolites AMPA and DDE were the only compounds detected with a frequency above 50\%. The herbicides glyphosate $(\mathrm{P})$ and oxyfluorfen (P) and the fungicide prochloraz (VP) presented frequencies between 20 and $50 \%$. Soils from $\mathrm{S}-\mathrm{O}-\mathrm{O}$ presented residues of glyphosate and AMPA along with high levels of DDT metabolites, with frequencies between 44 and 89\% (Table 3).

\subsubsection{Pesticide residues content in the CSS}

The highest pesticide content was found in $\mathrm{P}-\mathrm{G}-\mathrm{C}$, with a total residue content of nearly $12 \mathrm{mg} \mathrm{kg}^{-1}$, a value approximadetly 6 times higher than the maximum content in $\mathrm{N}-\mathrm{P}-\mathrm{C}$ and $\mathrm{S}-\mathrm{O}-\mathrm{C}$ fields, and 12 times higher than in $\mathrm{S}-\mathrm{V}-\mathrm{C}$ (with a maximum content of 2, 1.7 and $0.8 \mathrm{mg} \mathrm{kg}^{-1}$, respectively; Figs. 4 and 5). The residue content under organic farming in $\mathrm{N}-\mathrm{P}$ and $\mathrm{S}-\mathrm{V}$ did not exceed $0.2 \mathrm{mg} \mathrm{kg}^{-1}$, i.e. $10 \%$ of the maximum content in the respective conventional fields. In $\mathrm{S}-\mathrm{O}-\mathrm{O}$, the maximum residue content was $0.6 \mathrm{mg} \mathrm{kg}^{-1}$, which was about $30 \%$ of the maximum residue content of the conventional fields (Fig. 5). The residues that contributed the most to the total residue content under conventional farming systems were: (i) glyphosate and AMPA in P-G; (ii) glyphosate, AMPA and boscalid in N-P; (iii) boscalid and

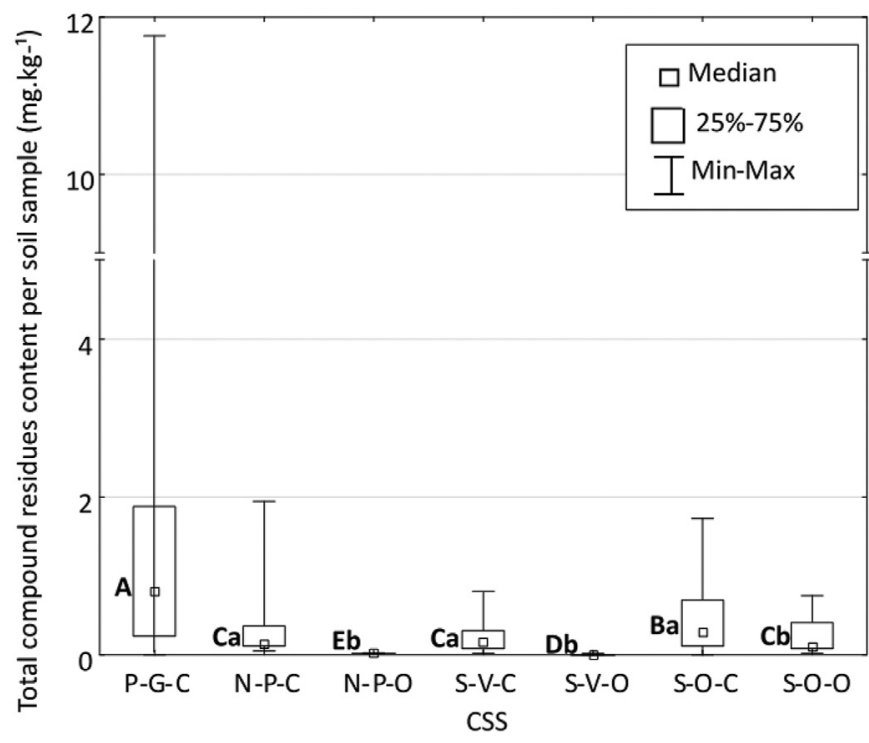

Fig. 5. Total pesticide residues content in soil samples. Significant differences among CSS with the same management system (Mann and Whitney $U$ Test, $\mathrm{p}<0.05$ ): A $>B>C$; and between organic and conventional fields from the same CSS: $a>b$. Southeast-Spain $(\mathrm{S}-\mathrm{V})$, orange production in Eastern Spain $(\mathrm{S}-\mathrm{O})$, grape production in Northern Portugal $(P-G)$, and potato production in Northern Netherlands $(\mathrm{N}-\mathrm{P})$, $\mathrm{C}=$ conventional, $\mathrm{O}=$ organic. imidacloprid in S-V; and (iv) AMPA and DDT metabolites in S-O. In organically managed fields, AMPA and DDT metabolites had the highest contributions, and specially for $\mathrm{S}-\mathrm{O}$; in the other organic farming systems, the total content was low.

\section{Discussion}

\subsection{Soil contamination status}

The levels of total pesticide content in soil in 3 out of the 4 CSS $(\mathrm{N}-\mathrm{P}, \mathrm{S}-\mathrm{V}$ and $\mathrm{S}-\mathrm{O})$ were in a range similar to those identified by Silva et al. (2019) for EU agricultural soils. Although most of the P-G samples were also within this range, some of them exceeded the maximum total content previously measured in EU soils, one of them by almost fourfold (12 versus $2.87 \mathrm{mg} \mathrm{kg}^{-1}$ ). The very high levels of residues in these samples were almost exclusively a consequence of the high levels of glyphosate and AMPA, suggesting an intense use of glyphosate-based herbicides in some farms in this area. Unfortunately P-G farmers application records did not cover glyphosate amounts, which if available could corroborate this. Environmental factors such as climate, soil type or the organic matter content, known to affect persistence of pesticides (Navarro et al., 2007; O'Loughlin et al., 2000), could also help explain our pesticide results. However, effects of environmental parameters were never explored at large scale (Vryzas, 2018). Our design does not allow such evaluations either because we focused on spatial coverage and selected the dominant crop per CSS to explore the impacts of organic and conventional management on soil quality. As we have only one crop per pedoclimatic region, we cannot differentiate the effects of the crop management from the effects of climate or soil properties. We encourage further studies to elucidate the comparative effects of the environmental parameters on pesticides persistency.

Finally, and although we analysed most of the compounds reported to be applied in these areas, as well as the most relevant banned pesticides (except in $\mathrm{S}-\mathrm{V}$ ), including a larger amount of residues into the analytical list would probably have revealed even more residues and higher pesticide levels in EU soils. This is however a common limitation of studies analysing pesticide residues; due to the high number of pesticides approved per crop and wide variety in physical chemical properties of these compounds, it is nearly impossible to analyse all of the residues potentially present in soils. As a result, we only get an approximate, yet likely underestimated, picture about the real soil contamination status.

\subsection{Possible effects of pesticide residue mixtures on soil health}

Although most of the products used by our CSS farmers were non-persistent pesticides, only 5 out of the 22 most frequent residues found in soils (i.e. $>20 \%$ in at least on CSS) are non- or moderately persistent ( $\mathrm{DT}_{50}$ values below 100 days). Although this is partly justified by our soil sampling times -in in P-G, S-V and $\mathrm{S}-\mathrm{O}$ there was a minimum of a month's time between the last pesticide application and the soil sampling, and in $\mathrm{N}-\mathrm{P}$, at least a 6 month interval - this observation corroborates existing concerns on long-term impacts of pesticides. What do we really know about the effects of accumulated pesticide residue mixtures on soil health? The current EC approach to approve pesticides for use on the European market considers soil health impacts based of single compound tests carried out on very few standard soil organisms (2 compost worm species: Eisenia fetida, E. andrei; 2 springtail species: Folsomia candida, F. fimetaria; 1 mite species: Hypoaspis aculeifer) and on N transformation organisms (Ockleford et al., 2017). Since this approach does not reflect the real effects on soil biota, the EFSA Scientific Committee (ICF, 2019) suggested the introduction of risk 
assessments related to residue mixtures that would test for the additive (default) or synergistic effects of compounds. Kosubová et al. (2020) already published risk assessments for soils based on the additive approach. However, data on toxicity (no effect concentrations, lethal and other effect concentrations) are mainly available only for the EFSA test organisms (PPDB, 2020). Considering the fact that soil biota consists of more than 1 million species, which provide different ecosystem functions such as nutrient and carbon cycling, water retention or pest suppression, it would be logical to expect that pesticide risk assessments should cover these functions. However, the effects of pesticide mixtures on these functions are rarely tested and scarce data are available. If the effects of pesticide mixtures are not known, several questions arise such as 'What concentrations of residues and what number of different residues can be considered a benchmark for soil health?' and 'When is pest suppressiveness significantly reduced?'. Some of these questions are highlighted by our findings:

i) Glyphosate along with its main metabolite AMPA and herbicides were dominantly present in the soils from P-G, N-P and $\mathrm{S}-\mathrm{O}$. Depending on the concentration and availability, glyphosate can kill all soil organisms that rely on the Shikimate pathway 1 for amino acid synthesis. Non-target organisms such as beneficial soil bacteria can also be killed. Unfortunately, soil-borne pathogens such as Fusarium fungi do not rely on the Shikimate pathway 1 and therefore, survive (Van Bruggen et al. 2018). This may therefore cause a decrease in the pest supressiveness of glyphosate treated soils and ultimately lead to higher fungicide applications (see Table 2) and more accumulated residues in soil. Although the combined effects of glyphosate, AMPA, and fungicide residues in soils on nutrient cycling has not been studied yet, we expect that the phosphorus cycle in the soil will be strongly affected by synergetic effects due to the fact that mycorrhiza, the fungi essential to the P availability in soils, is killed by glyphosate and fungicides. This combined effect should be a central part of all the discussions surrounding plant growth and phosphorus availability.

ii) Soil samples from the S-V CSS presented relatively fewer pesticide residues than the other CSS. Plastic mulch was extensively used in this area and therefore, fewer pesticides were used (Beriot et al., 2020). Glyphosate was not used in the S-V CSS, with pendimethalin being used instead as the main herbicide. Together with imidacloprid and boscalid, these were the most dominant residues found in $\mathrm{S}-\mathrm{V}$. The synergetic effects of the main residues present in $\mathrm{S}-\mathrm{V}$, in combination with the microplastics present in these soils as a result of years of plastic mulch applications have not been studied sufficiently (Qi et al., 2020).

iii) DDT metabolites were still present in many soils, especially in $\mathrm{S}-\mathrm{O}$ where they contributed significantly to the residue mixtures, even on organic farms. In $\mathrm{S}-\mathrm{V}$, we did not analyse the residues of banned pesticides, we focused only on approved ones. We assume that this fact could partly explain the lower number of residues found in S-V. Again, several questions arise such as 'What is the combined effect of the DDTs inhibiting Gaba Synthesis and AMPA?' 'Are the soil insects strongly affected by the dual effects: direct effects via Gaba inhibition and indirect effects due to changes in the gut microbiome?' 'Is AMPA killing the beneficial bacteria in the gut microbiome?".

These questions are posed to illustrate the complexity of the topic and the difficulties facing realistic risk assessment approaches. Researchers need to define the requirements for innovative tests, taking into consideration the fact that soils in Europe are contaminated after 70 years of pesticide applications. Furthermore, tests should examine the effects of residue mixtures on soil functions. Policy makers should consider researchers to establish benchmarks related to the content and the number of pesticide residues in order to protect soil health. Since soil health covers the capacity of soils to support ecosystem services such as clean air and water, genetic resources or pollination (Maes et al., 2015; Costanza et al., 2017), all these may be jeopardized if soil diversity is under risk with the presence of pesticide cocktails.

\subsection{Organic agriculture}

Comparing conventional and organic management systems, we identified $30 \%$ less pesticide residues in the organic systems. The residues common to both systems presented 70-90\% lower concentrations in organic soils than in conventional soils. The typical half-life of residues detected in organic fields ranged from 100 days to more than a year. Although synthetic pesticides are not applied under organic farming (Reganold and Wachter, 2016) soils under organic farming may contain pesticide residues (Witczak and Abdel-Gawad, 2012). The European Commission requires a conversion time of two years of organic management before certification for annual crops (EC 2008b), which means that the content of very persistent compounds in soil $\left(\mathrm{DT}_{50}>1\right.$ year) at the time an organic crop is finally harvested will be $1 / 4$ of the content that the crop would have had at the start of the organic conversion. This estimation shows that the conversion time allows for a reduction of pesticide residues in soil but not to their complete disappearance. The levels of the most persistent compounds are not really affected in time, as corroborated by the still relatively high levels of DDTs measured in organic fields, especially in $\mathrm{S}-\mathrm{O}-\mathrm{O}$. Because DDT has been banned in many European countries since the 1970s (including those selected for this analysis) and in all EU countries since 2009 (EC, 2009b), the concentrations measured were probably from historical applications. For other less persistent residues, the contamination could be result of applications carried out before the farm converted to organic farming or, for instance, via spray drift and deposition after a neighbouring conventional field was sprayed.

In order to guarantee minimal levels of pesticide residues in soils, conversion to organic farming requires adapted transition periods depending on the residue mixtures initially present in the soils. Studies on the uptake of the different pesticide residues by plants are urgently required to define threshold values for soils. Planning financial support for farmers transitioning to organic farming should take this fact into consideration. Different environmental policies should also be established to stimulate farmers who seek to grow food and feed with less impact on the environment. The possibility of soil remediation should be made a priority in places where it is feasible. Moreover, the establishment of rich above-ground plant systems may mitigate the effect of historical and current pesticides in soils.

\subsection{Food safety}

Although the focus of this study has been on soil health, researchers know that pesticide residues in soils can enter the food chain and therefore can affect food quality and human health (Brevik et al., 2020; Carre et al., 2015). Contrary to EU soils, EU food products are exhaustively monitored every year for pesticide residues, in line with the Regulation No 396/2005 concerning maximum residue levels (MRLs) of pesticides in or on food and feed of plant and animal origin (EC, 2005). According to the latest EFSA 
monitoring report (EFSA, 2020), 48\% of the 91,015 EU tested food products contained pesticide residues. Organically produced food seems to result in a lower burden of pesticides than conventionally produced food: 13.8 versus $46 \%$ of samples contained pesticide residues, and 1.4 versus $4.8 \%$ of samples had measurements exceeding current MRLs, respectively. However, if the total pesticide content in food products is not considered, individual MRL exceedance percentages might be misleading and not be a realistic reflection of the risk posed by contaminated food products. The dietary risks of pesticides in foods may be greater since $29 \%$ of the food samples tested had multiple residues, with a maximum of 29 different residues per sample (EFSA, 2020). Vegetables and fruits (the crops in three of our four CSS, and commonly assumed to be the healthiest food products) are among the food items most likely to be contaminated by cocktails of residues (EFSA, 2020). Although EU-harmonised MRLs are available for 495 pesticide residues and for 381 food products, MRLs exist only for a few metabolites and not exist for total pesticide content (EU Pesticide database, 2020). Furthermore, there are no specific MRLs for organic products (EU, 2018). MRLs should be quickly established for pesticide residue mixtures in food and should relate to total MRLs for the sum of all residues as well as to the total number of residues. These MRLs should be significantly lower for organically produced foods as compared to conventionally produced foods.

Only a couple of the pesticide residues found in our CSS soils were present in more than $5 \%$ of the EU food samples (azoxystrobin and boscalid). Glyphosate, prosulfocarb, boscalid, metalaxyl, and tebuconazole exceeded their respective MRLs occasionally (EFSA, 2020). DDTs were also found in a few food products, including organic samples, and most likely originated from the soil (EFSA, 2020). Although some parallelism can be drawn between our observations in EU soils and EFSA and FAO pesticide data on food products, a direct conversion between matrices, or between chemical data and health impacts, cannot be done. On one hand, pesticide application might not reach the harvested product (in the case of early season pesticide applications as well as in the case of herbicides that are often only applied to the base of tree trunks or vines in orchards). In these situations, soil contamination is far more likely than food contamination. For vegetables and root crops grown in-soil or on the soil surface, food contamination might still be possible. On the other hand, food contamination might occur not in the field but during handling, packaging, storage or processing of food products, including organic food product.

\subsection{Implementation of the farm to Fork Strategy}

The Farm to Fork Strategy (EC, 2020) sets an EC target to reduce the use and the risk of chemical pesticides by $50 \%$ by 2030 , and the reduction of the more hazardous pesticides by $50 \%$ also by 2030 . For the first time, a quantified pesticide reduction target at the EU level has been set. Moreover, this same Farm to Fork Strategy encourages organic farming with the aim of having at least $25 \%$ of EU agricultural land under organic farming management by 2030. As shown by this study, although the accumulated residue content in organic soils was $70-90 \%$ lower than in conventionally managed soils, some soils still contain between 2 and 5 residues, even after more than 10 years of organic farming. Our results raise two main questions related to the Farm to Fork strategy that should be addressed on the short term:

i) Which pesticide mixtures pose the highest risk to soil health and which pesticides should preferably be subject to use restrictions or even banned? To answer these questions, a new approach to risk assessment should be implemented by EFSA and EC procedures in due time, considering pesticide cocktails occurring on the major agricultural systems and crops.

ii) Benchmarks for residue cocktails are required for soils from certified organic farms. In effect, only management requirements are regulated through the European level Regulation (EC) No 834/20072 and Regulation (EC) No 889/20083. Persistent synthetic pesticide residues in soils are not taken into account since they are not applied in organic farming. However, > $80 \%$ of the soils in Europe (Silva et al., 2019), contain residues. Even assuming that all these originate from conventionally managed farms, part of these soils are likely to be converted to organic soils during the coming years, and therefore there should be clear regulations to guarantee that certified organic products are not affected by environmental contamination. Benchmarks for residues in soils are urgently required.

\section{Conclusions}

- Mixtures of pesticide residues were present in all case study sites under conventional farming, both in samples taken at the start of the crops season, and samples taken post-harvest.

- In organic soils, the residue levels were 70-90\% lower than in conventional fields, however, most of the organic soils contained residue mixtures as well.

- The overall effect of the cocktails on soil health is unknown. Innovative tests are urgently required to test the effects of detected pesticide cocktails on soil health in a holistic way, before approving new pesticides for the EC market.

- Benchmarks must be defined for pesticide residue cocktails in all agricultural systems in order to protect soil health, soil biodiversity and food quality.

- The time required for transitioning to (certified) organic farming should also depend on the pesticide residues mixtures in the soil at the starting point of the transition.

\section{Credit author statement}

Violette Geissen: Conceptualization, resources, funding acquisition, writing original and final draft. Vera Silva: Conceptualization, Data collection and data analysis, writing original and final draft. Esperanza Huerta Lwanga: Data collection and data analysis, elaboration of figures and tables, revision and editing of the original draft. Nicolas Beriot: Data collection and analysis, elaboration of figures and tables, writing of reference chapter, revision and editing of the original draft. Klaas Oostindie: Elaboration of final figures and tables, visualization. Zhaoqi Bin: Data collection and analysis. Erin Pyne: Data collection and analysis, revision and editing of the original draft. Sjors Busink: Data collection and analysis. Paul Zomer: Pesticide analysis, revising and editing the original draft. Hans Mol: Pesticide analysis, revising and editing the original draft. Coen Ritsema: Conceptualization, resources, funding acquisition, review \& editing of the original draft.

\section{Declaration of competing interest}

The authors declare that they have no known competing financial interests or personal relationships that could have appeared to influence the work reported in this paper.

\section{Acknowledgments}

The research leading to these results has received funding from (i) the European Union Seventh Framework Programme (FP7/ 2007-201) project RECARE [grant $n^{\circ}$ 603498], (ii) the EU Horizon 
2020 project Interactive Soil Quality Assessment in Europe and China for agricultural productivity and environmental resilience iSQAPER [grant $n^{\circ} 635750$ ] , and (iii) the EU Horizon 2020 project DIVERFARMING [grant $\mathrm{n}^{\circ}$ 728003].

\section{Appendix A. Supplementary data}

Supplementary data to this article can be found online at https://doi.org/10.1016/j.envpol.2021.116827.

\section{References}

Bento, C.P.M., Yang, X.M., Gort, G., Xue, S., van Dam, R., Zomer, P., et al., 2016. Persistence of glyphosate and aminomethylphosphonic acid in loess soil under different combinations of temperature, soil moisture and light/darkness. Sci. Total Environ. 572, 301-311.

Beriot, N., Zomer, P., Zornoza, R., Geissen, V., 2020. A laboratory comparison of the interactions between three plastic mulch types and 38 active substances found in pesticides. PeerJ 8, e9876. https://doi.org/10.7717/peerj.9876.

Bevan, R., Brown, T., Matthies, F., Sams, C., Jones, K., Hanlon, J., La Vedrine, M., 2017. Human biomonitoring data collection from occupational exposure to pesticides. EFSA Support. Publ. 14 (3), 1185E. https://doi.org/10.2903/sp.efsa.2017.EN-1185.

Brevik, E.C., Slaughter, L., Singh, B.R., Steffan, J.J., Collier, D., Barnhart, P., Pereira, P., 2020. Soil and human health: current status and future needs. Air Soil. Water Res. 13, 1-23.

Carre, F., Caudeville, J., Bonnard, R., Bert, V., Boucard, P., 2015. Soil contamination and human health : a major challenge for global soil security. In: Global Soil Security Symposium, May 2015, College Station, United States, pp. 275-295. https://doi.org/10.2903/sp.efsa.2017.EN-1185.

Casado, J., Brigden, K., Santillo, D., Johnston, P., 2019. Screening of pesticides and veterinary drugs in small streams in the European Union by liquid chromatography high resolution mass spectrometry. Sci. Total Environ. 670, 1204-1225. https://doi.org/10.1016/j.scitotenv.2019.03.207.

Colin, T., et al., 2019. Traces of a neonicotinoid induce precocious foraging and reduce foraging performance in honey bees. Environ. Sci. Technol. https:// doi.org/10.1021/acs.est.9b02452.

Costanza, R., et al., 2017. Twenty years of ecosystem services: how far have we come and how far do we still need to go? Ecosyst. Serv. 28 (Part A), 1-16. https:// doi.org/10.1016/j.ecoser.2017.09.008. ISSN 2212-0416.

EC, 2005. European Commission Regulation (EC) NO 396/2005 of the European Parliament and of the Council of 23 February 2005 on maximum residue levels of pesticides in or on food and feed of plant and animal origin and amending Council Directive 91/414/EEC. Off. J. Eur. Union L 70, 1-16. http://data.europa. eu/eli/reg/2005/396/oj.

EC, 2008a. European Commission Regulation (EC) of the European Parliament and of the Council of 16 December 2008 on classification, labelling and packaging of substances and mixtures, amending and repealing Directives 67/548/EEC and 1999/45/EC, and amending Regulation (EC) No 1907/2006. https://eurOff.J.Eur. Union-Llex.europa.eu/eli/reg/2008/1272/oj/eng.

EC, 2008b. European Commission Regulation (EC) No 889/2008 of 5 September 2008 laying down detailed rules for the implementation of Council Regulation (EC) No 834/2007 on organic production and labelling of organic products with regard to organic production, labelling and control. http://data.europa.eu/eli/ reg/2008/889/oj.

EC, 2009a. European Commission Regulation (EC) No 1107/2009 of the European Parliament and of the Council of 21 October 2009 concerning the placing of plant protection products on the market and repealing Council Directives 79/ 117/EEC and 91/414/EEC. http://data.europa.eu/eli/reg/2009/1107/oj.

EC, 2009b. European commission regulation (EC) No 850/2004 of the European parliament and of the council of 29 april 2004 on persistent organic pollutants and amending directive 79/117/EEC. http://data.europa.eu/eli/reg/2004/850/ 2009-05-05.

EC, 2015. Directorate-general for Health and Food Safety, Safety of the Food Chain Pesticides and Biocides, SANTE/11945/2015, Guidance document on analytical quality control and method validation procedures for pesticides residues analysis in food and feed. Supersedes SANCO/12571/2013. https://www.eurlpesticides.eu/library/docs/allcrl/AqcGuidance SANTE 2015 11945.pdf.

EC, 2017. Directorate-general for Health and Food Safety, Safety of the Food Chain Pesticides and Biocides, SANTE/11813/2017, Guidance document on analytical quality control and method validation procedures for pesticide residues and analysis in food and feed. https://ec.europa.eu/food/sites/food/files/plant/docs/ pesticides_mrl_guidelines_wrkdoc_2017-11813.pdf.

EC, 2020a. Communication from the commission to the European parliament, the council, the European economic and social committee and the committee of the regions - a farm to Fork strategy for a fair, healthy and environmentally-friendly food system. Brussels, 20.5.2020 - $\operatorname{COM(2020)} 381$ final. https://ec.europa.eu/ food/farm2fork en.

EC, 2020b. Communication from the commission to the European parliament, the council, the European economic and social committee and the committee of the regions - EU biodiversity strategy for 2030 - bringing nature back into our lives. Brussels, 20.5.2020. COM(2020) 380 final. https://ec.europa.eu/info/sites/info/ files/communication-annex-eu-biodiversity-strategy-2030_en.pdf.

EFSA - European Food Safety Authority, Medina-Pastor, P., Triacchini, G., 2020. The 2018 European Union report on pesticide residues in food. EFSA J. 18 (4), 103. https://doi.org/10.2903/j.efsa.2020.6057.

EFSA Scientific Committee, More, S.J., Bampidis, V., Benford, D., Bennekou, S.H., et al., 2019. Guidance on harmonised methodologies for human health, animal health and ecological risk assessment of combined exposure to multiple chemicals. EFSA J. 17 (3), 5634. https://doi.org/10.2903/j.efsa.2019.5634.

EU, 2018. European union regulation (EU) 2018/848 of the European parliament and of the council of 30 may 2018 on organic production and labelling of organic products and repealing council regulation (EC) No 834/2007. http://data.europa. eu/eli/reg/2018/848/oj.

EU Pesticide database, 2020. Search active substances. Last access 29 June 2020 https://ec.europa.eu/food/plant/pesticides/eu-pesticides-database/public/? event=activesubstance.selection\&amp;language $=\mathrm{EN}$.

EUROSTAT, 2017. Archive: pesticide sales statistics. https://ec.europa.eu/eurostat/ statistics-explained/index.php?title=Archive:Pesticide_sales_statistics\&amp; oldid=327059\#Further Eurostat information.

FAOSTAT, 2019. Pesticides use data. http://www.fao.org/faostat/en/\#data/RP.

Grubisic, M., van Grunsven, R.H.A., Kyba, C.C.M., Manfrin, A., Hölker, F., 2018. Insect declines and agroecosystems: does light pollution matter? Ann. Appl. Biol. 173 (2), 180-189. https://doi.org/10.1111/aab.12440.

Hallmann, C.A., Sorg, M., Jongejans, E., Siepel, H., Hofland, N., Schwan, H., et al., 2017. More than 75 percent decline over 27 years in total flying insect biomass in protected areas. PloS One 12 (10), e0185809. https://doi.org/10.1371/ journal.pone.0185809.

ICF, 2019. EU Insights - chemical mixtures: awareness, understanding and risk perceptions. EFSA Support. Publ. 16 (3), 113. https://doi.org/10.2903/sp.efsa.2019.EN-1602.

Jouni, F., et al., 2020. 'Elucidating pesticide sensitivity of two endogeic earthworm species through the interplay between esterases and glutathione S-transferases'. Chemosphere, 127724. https://doi.org/10.1016/ j.chemosphere.2020.127724.

Kosubová, P., Škulcová, L., Poláková, Š., Hofman, J., Bielská, L., 2020. Spatial and temporal distribution of the currently-used and recently-banned pesticides in arable soils of the Czech Republic. Chemosphere 254, 126902.

Maes, J., Barbosa, A., Baranzelli, C., et al., 2015. More green infrastructure is required to maintain ecosystem services under current trends in land-use change in Europe. Landsc. Ecol. 30, 517-534. https://doi.org/10.1007/s10980-014-0083-2.

Motta, E.V.S., Raymann, K., Moran, N.A., 2018. Glyphosate perturbs the gut microbiota of honey bees. Proc. Natl. Acad. Sci. Unit. States Am. 115 (41), 10305.

Navarro, S., Vela, N., Navarro, G., 2007. Review. An overview on the environmental behaviour of pesticide residues in soils. Spanish J. Agric. Res. 5 (3), 357-375, 1695-971-X

Ockleford, C., Adriaanse, P., Berny, P., Brock, T., Duquesne, S., Grilli, S., et al., 2017. Scientific opinion addressing the state of the science on risk assessment of plant protection products for in-soil organisms. EFSA J 15.

Oyeleke, S.B., Oyewole, O., Dagunduro, J., 2011. Effect of herbicide (pendimethalin) on soil microbial population. J. Food Agric. Sci. 13, 40-43.

O'Loughlin, E.J., Traina, S.J., Sims, G.K., 2000. Effects of sorption on the biodegradation of 2-methylpyridine in aqueous suspensions of reference clay minerals. Environ. Toxicol. Chem. 19 (9), 2168-2174. https://doi.org/10.1002/ etc.5620190904.

Pereira, J.L., et al., 2009. Toxicity evaluation of three pesticides on non-target aquatic and soil organisms: commercial formulation versus active ingredient. Ecotoxicology 18 (4), 455-463. https://doi.org/10.1007/s10646-009-0300-y.

PPDB, 2020. Pesticide properties DataBase. University of Hertfordshire. https:// sitem.herts.ac.uk/aeru/ppdb/en/atoz.htm.

Qi, Y., Beriot, N., Gort, G., Huerta Lwanga, E., Gooren, H., Yang, X., Geissen, V., 2020. Impact of plastic mulch film debris on soil physicochemical and hydrological properties. Environ. Pollut. 266, 115097.

Reganold, J., Wachter, J., 2016. Organic agriculture in the twenty-first century. Nat. Plants 2, 15221. https://doi.org/10.1038/nplants.2015.221.

Sánchez-Bayo, F., Wyckhuys, K.A.G., 2019. Worldwide decline of the entomofauna: a review of its drivers. Biol. Conserv. 232, 8-27. https://doi.org/10.1016/ j.biocon.2019.01.020.

Silva, V., Mol, H.G.J., Zomer, P., Tienstra, M., Ritsema, C.J., Geissen, V., 2019. Pesticide residues in European agricultural soils - a hidden reality unfolded. Sci. Total Environ. 653, 1532-1545. https://doi.org/10.1016/j.scitotenv.2018.10.441.

Tiwari, Rishikesh K., et al., 2016. Enzymes of earthworm as indicators of pesticide pollution in soil. Adv. Enzym. Res. 4 (4), 11.

Uwizeyimana, H., Wang, M., Chen, Weiping, Khan, Kifayatullah, 2017. The eco-toxic effects of pesticide and heavy metal cocktails towards earthworms in soil. Environ. Toxicol. Pharmacol. 55, 20-29. https://doi.org/10.1016/j.etap.2017.08.001.

Van Bruggen, A.H.C., He, M.M., Shin, K., Mai, V., Jeong, K.C., Finckh, M.R., 2018. Environmental and health effects of the herbicide glyphosate. Sci. Total Environ. 616, 255-268. https://doi.org/10.1016/j.scitotenv.2017.10.309.

Vryzas, Z., 2018. Pesticide fate in soil-sediment-water environment in relation to contamination preventing actions. Curr. Opin. Environ. Sci. Health 4 (5-9). https://doi.org/10.1016/j.coesh.2018.03.001. ISSN 2468-5844.

Wang, X., et al., 2020. Fungicide azoxystrobin induced changes on the soil 
microbiome. Appl. Soil Ecol. 145 https://doi.org/10.1016/j.apsoil.2019.08.005.

Willer, H., Lernoud, J. (Eds.), 2019. The World of Organic Agriculture. Statistics and Emerging Trends 2019. Research Institute of Organic Agriculture (FiBL), Frick, and IFOAM - Organics International, Bonn. https://shop.fibl.org/chen/ mwdownloads/download/link/id/1202.

Witczak, A., Abdel-Gawad, H., 2012. Comparison of organochlorine pesticides and polychlorinated biphenyls residues in vegetables, grain and soil from organic and conventional farming in Poland. J. Environ. Sci. Health, Part B 47 (4), 343-354. https://doi.org/10.1080/03601234.2012.646173.

Yang, X.M., Wang, F., Bento, C.P.M., Xue, S., Gai, L.T., van Dam, R., et al., 2015. Shortterm transport of glyphosate with erosion in Chinese loess soil - a flume experiment. Sci. Total Environ. 512, 406-414. 